\title{
Improving the uptake of flood risk adaptation measures for domestic properties in an insurance regime under transition
}

\author{
D. Cameron ${ }^{1} \&$ D. Proverbs ${ }^{2}$ \\ ${ }^{1}$ Bristol City Council, UK \\ ${ }^{2}$ University of the West of England, $U K$
}

\begin{abstract}
In June 2013 the UK Government and the ABI announced plans for a new system of insurance called 'Flood Re'. This announcement was the first step towards setting up a 'not for profit' scheme which aims to ensure the continuation of affordable insurance for households with the highest flood risk. This research investigates whether the widespread provision of flood insurance is a factor in the low uptake of property level resilience measures. In the context of transition it further examines whether there is growing impetus for the concept of incorporating such measures. The literature establishes that the historic insurance regime provided few incentives for installation of flood resilience measures and that there are a number of factors beyond the provision of insurance which influence the low uptake of measures. The impact of potential changes in the insurance regime is explored in more detail through a number of semi-structured interviews with key flood risk management professionals and academics. The research finds that links between the provision of insurance and the installation of resilience measures are significant. Flood resilience measures will continue to be part of the wider strategy of community engagement with an integrated approach to flood risk management. The newly proposed 'Flood Re' is intended to be a transitory measure that will allow householders to adapt and take the necessary measures to protect themselves. However, in the long term, the anticipated move towards risk based pricing in whatever form may provide better incentives to households to adapt and this could be reinforced by other measures to support households in adaptation.
\end{abstract}

Keywords: adaptation, flood risk management, insurance, resilience. 


\section{Introduction}

Flooding is the biggest natural threat facing the UK and flood risk is predicted to increase due climate change, development and the gradual deterioration of flood defence assets (ABI [1]). The UK has benefited from a private insurance system for flood risk that has existed for over half a century and this has formed the main source of financial protection for households in flood risk areas. A series of agreements were in place between the government and the insurance industry which ensured that the majority of households had access to affordable insurance for flooding. These started with what was referred to as the 'Gentleman's Agreement' and more recently the 'Statement of Principles on the provision of flood Insurance' (DEFRA [2]). On the 27th of June 2013, the Government and the insurance industry announced a new agreement which would guarantee the availability of insurance for households in flood risk areas. The preferred solution would be an industry-run, not-for-profit scheme called 'Flood Re'. This scheme will effectively cap the maximum amount paid by the $1-2 \%$ of households at highest risk of flooding. It would be funded by an industry backed levy set to be $£ 180$ million per year for the first 5 years, an equivalent of $£ 10.50$ for every UK household. It will take time for 'Flood Re' to become operational and therefore the insurance industry has voluntarily agreed to abide by the Statement of Principles until such a time that 'Flood Re' can be introduced (DEFRA [2]).

The considerable uncertainty surrounding the decision over the future of household flood insurance, together with an increased frequency of flood events, has resulted in increased awareness of the concept of incorporating flood resilience at property level. However, uptake of these measures remains low. In 2008, DEFRA announced less than 5000 homes have adopted flood resilient and resistance measures (Bichard and Kazmierczak [3]). To encourage an increase in uptake in resilience measures DEFRA launched its property level flood protection scheme. The 2 year programme ran until March 2011 and it delivered £5.2 million to 1,109 households, the average cost to households for these measures was $£ 4,832$ (Environment Agency [4]). Whilst the UK Government has sought to influence householders to take up flood protection measures, the strategies employed have not been as successful as they had hoped (Bichard and Kazmierczak [3]). One reason for this could be that the wide availability of insurance to households has distorted their perception of risk. This study therefore sought to investigate the extent to which the widespread provision of flood insurance is contributing to the low uptake of property level resilience measures.

\section{A background into flood insurance and resilience}

Despite the increased frequency of flood events it is apparent that take up of flood resilience measures is still low amongst householders. As insurance is still the main source of financial protection for domestic households, it is important to establish how insurance influences decision of those most at risk of flooding of whether or not to install additional protection in their property. 


\subsection{Flood Resilience technology (FRe)}

Resilience is defined as the ability of system/community/society/defence to react to, and recover from, the damaging effect of realised hazards. The definition of resistance is the ability of systems to remain unchanged by external events (SMARTeST [5]). In the context of flooding these terms are used to describe different methods of protecting property and communities. Flood resistance or dry proofing methods attempt to keep the flood water out of the property; these are only suitable methods for floods up to a certain depth. Flood resilience measures allow the water to enter the property but then enable the drying and recovery process to be undertaken swiftly. Contemporary thought is that these methods should not be thought of in isolation. For example, the SMARTest project describes these and other methods under the umbrella term of Flood Resilience technologies (FRe). Here they try to steer away from the term property level protection because some of the products, such as demountable barriers are used at a community level, and others do not offer full protection, they merely speed up the recovery (White et al. [6]). FRe Technologies can be important in smaller communities where it is not cost beneficial to consider large scale flood defence systems (Kazmierczak and Connelly [7]). Flooding comes from multiple sources, and FRe technologies can be considered more flexible and adaptable when dealing with surface water and flash flooding (White et al. [6]).

The Adaptation Sub-Committee reported that the uptake of such measures is considered to be 20-35 times lower than the rate needed to reach all of the properties that could potentially benefit within a reasonable timeframe Adaptation Sub-committee [8]. They also predict that by increasing investment in flood defences and property protection measures, the number of properties at risk could be halved by 2035 , which adds economic weight to the case for property level protection.

\subsection{Flood insurance beyond 2013}

The Government and the ABI have agreed upon a Memorandum of Understanding which sets out how 'Flood Re' is likely to operate in order to progress with the development of Government policy. However, there are still many issues which need to be resolved. The Government are to introduce new legislation in the Water Bill to enable the introduction of 'Flood Re'. The main powers will be to compel all insurers offering household insurance to participate in 'Flood Re' and provide for 'Flood Re' to be funded through an industry levy (DEFRA [2]). Householders should be aware that 'Flood Re' will be a transitional measure, intended to be phased out within 20-25 years. A 'Sunset Clause' will be included in the primary legislation to set an expiry date for 'Flood Re', as well as powers to ensure the orderly winding down of the scheme (DEFRA [2]). The policy objective is that there should be a gradual transition towards risk reflective pricing (a free market), which is intended to increase incentives for flood risk to be managed properly. The Government intends to seek powers in the Water Bill to allow them to stand ready to regulate if 'Flood Re' can't be made to work for consumers and insurers. This 'Flood Insurance Obligation' will require insurance companies to insure a 
proportion of properties from a register of high risk households. This should create a level playing field and overcome the competitive pressures on insurers to withdraw from flood risk areas (DEFRA [2]).

\subsection{Property protection and insurance}

In the current insurance market, there is very little to suggest that the installation of FRe technology to protect property will result in reduced premiums and excesses for householders. A number of surveys have concluded that for the majority, there was no evidence to suggest the installation of FRe technologies would result in cheaper insurance (Bell [9]; Cobbing and Miller [10]; Harries [11]). The way in which resistance and resilience measures can help is by avoiding the need to involve insurance companies, or reducing the size of the claim made. This can help to maintain access to mainstream insurance but is little incentive for the installation of such measures.

For individual properties, and for those properties in areas that flood frequently, FRe technology can be a cost effective means of reducing damage and disruption (Harries [11]). However, many people perceive that flood resilience measures may adversely affect property value or make their properties harder to sell. This is perhaps a genuine concern; research by Lamond et al. [12] found that many property buyers and sellers are often unaware of the flood risk to their property. In fact there is evidence to suggest that flood prone properties aren't discounted in price over the long term. This was illustrated by Lamond et al. [12] who point to properties in Bewdley which showed dips in value following flood events in 2001 and 2002. However, over the long term their value recovered (cited in Lamond [p. 332, 13]). These measures therefore could be seen as a deterrent for potential buyers. This perceived barrier is something which needs to be overcome.

\subsection{Moral hazard}

There is a longstanding and growing debate that the provision of insurance may prevent some from taking the necessary steps to protect themselves (Priest et al. [14]; Lamond and Proverbs [15]; Harries [16]; O'Neill and O'Neill [17]). The term 'Moral Hazard' is defined by O'Neill and O'Neill [17] as a situation in which individuals or organisations do not bear the costs of a particular risk and hence lack incentives to change behaviour to reduce that risk. The question of 'Moral Hazard' has been raised with regards to the behaviour of homeowners in protecting their own properties. It is used when there is a tendency towards less responsible behaviour by those who believe they are insulated from financial risk by insurance (Harries [16]). Understanding 'Moral Hazard' on behalf of the homeowner is critical to ensuring that a system of insurance is put in place which encourages homeowners to protect themselves. A balance needs to be found between providing affordable cover for those who need it and encouraging some form of self-protection which will reduce the impact of a future flood event. The difficulty with this is that if insurance is the default position, and it is also widely available, then policy holders are unlikely to consider other avoidance strategies (Lamond et al. [12]). 


\subsection{Standards for resilient reinstatement}

To eliminate this 'Moral Hazard', insurance companies could encourage homeowners to install FRe by providing incentives for adaptation measures. Botzen and Van Den Bergh [18] explain that insurance companies could limit damage by rewarding well designed buildings with lower premiums. An existing property that is reinstated with resistant or resilient measures could be rewarded with a reduced premium rate or lower excesses. The ability of insurance companies to provide incentives for flood mitigation measures would be a critical driver for the uptake of FRe technologies. To do this, insurers would need to know that the measures would actually work in practice. White et al. [19] stated that "The major insurers are key to driving FRe, but they need to be assured that their installation, maintenance, and performance means they can price effectively". Trust is therefore a key theme if FRe technology is ever going to reduce householder's premiums. To build that trust, standardisation is needed. Boobier [20] explains that standards are essential to ensure that the minimum acceptable level of repair is carried out. Currently there is no definitive set of standards for resilient repair, although some may fall under the control of building regulations. There are many publications which outline codes of practice and propose sets of benchmarks. However, none have yet been universally adopted. Kidd et al. [21] explain that "although the use of guidance is generally widespread...during a major emergency it is generally less adhered to". For resilient and resistant repair to make a difference to householders premiums, strict building codes would need to be in place and regulations would need to be enforced to ensure that buildings meet the required standard before the work is rewarded (Botzen and Van den Bergh [18]).

\section{Research design method and analysis}

The current uncertainty over the future of flood insurance and the dynamic of the discussions between the $\mathrm{ABI}$ and the Government meant that the situation was evolving as this research developed. A series of semi-structured interviews was undertaken with key stakeholders just prior to an agreement being announced. The aim of these interviews was to explore the opinions of individuals who understand different aspects of the flood recovery process.

The questions which were devised for the interviews were influenced directly from the issues and topics arising from the literature review. The questions were placed into three categories: 1) General Insurance Questions. 2) Resistance and resilience, and 3) Accountability and Training. Table 1 presents a summary of these questions.

The interviewees were chosen because of their credentials within the FRM community. Many have contributed research which was studied as part of the literature review, and some belong to organisations which form an important part of the flood recovery process. All have influence within their specialisation or organisation and have a depth of knowledge relating to FRM that was perceived to be beneficial to this study.

A summary of the interviewees is presented in Table 2. 
Table 1: Presentation of the questions asked to the interviewees.

\begin{tabular}{|c|c|}
\hline & General insurance questions \\
\hline Question 1 & $\begin{array}{l}\text { Do you think that the widespread provision of flood insurance } \\
\text { under the Statement of principles may have caused } \\
\text { complacency amongst householders to provide property level } \\
\text { protection against flood risk? }\end{array}$ \\
\hline \multirow[t]{2}{*}{ Question 2} & $\begin{array}{l}\text { Uptake of property level flood adaptation measures has been } \\
\text { low. What could be done to persuade householders to take up } \\
\text { flood mitigation measures? }\end{array}$ \\
\hline & Resistance and resilience \\
\hline Question 3 & $\begin{array}{l}\text { What do you think is the role of resistance and resilience in } \\
\text { reducing flood risk? }\end{array}$ \\
\hline Question 4 & $\begin{array}{l}\text { Whose responsibility is it to encourage and promote the use of } \\
\text { property level protection? How could insurers help promote } \\
\text { the uptake of such measures? }\end{array}$ \\
\hline \multirow[t]{2}{*}{ Question 5} & $\begin{array}{l}\text { Should financial incentives be provided for the installation and } \\
\text { purchase of resistance and resilience products for those } \\
\text { properties at high risk of flooding? If so, in what form could } \\
\text { these incentives take? }\end{array}$ \\
\hline & Accountability and training \\
\hline Question 6 & $\begin{array}{l}\text { Flood events are very unpredictable. What could then be done } \\
\text { to develop a way of monitoring the performance of flood } \\
\text { resistant and resilient materials? }\end{array}$ \\
\hline Question 7 & $\begin{array}{l}\text { Do you feel that building professionals have the necessary } \\
\text { training/experience to deal effectively with householders that } \\
\text { have experienced a flood? }\end{array}$ \\
\hline Question 8 & $\begin{array}{l}\text { Do you think England can learn lessons on flood policy from } \\
\text { other parts of the world? }\end{array}$ \\
\hline
\end{tabular}

\subsection{Method of analysis}

Due to the large volumes of data it was important to adopt a method of analysis which made sense of the information and presented the findings in a logical and coherent way. The transcripts were analysed using methods adapted from the hermeneutic analysis method. 'Hermeneutics' is characterised by Haigh [22] as examining the inter-relationship of the response from the interviews and relating this to the aims of the research at large. In this case, one of the main challenges was ensuring that the analysis remained focused upon the aims and objectives of this thesis. 
Table 2: Credentials of the interviewees.

\begin{tabular}{ll}
\hline Interviewee & \multicolumn{1}{c}{ Credentials and organisation } \\
\hline A & Professional/surveyor \\
B & Professional/surveyor \\
C & Insurance expert \\
D & Researcher/academic \\
E & Researcher/academic \\
F & Risk expert \\
G & Community spokesperson \\
\hline
\end{tabular}

\section{Analysis of interviews}

The majority of Interviewees acknowledged that there was a link between the availability of affordable insurance and households protecting their own properties. The general feeling was that if people had always been paid out on insurance then they would not be motivated to protect their property. However, Interviewees $\mathrm{C}$ and $\mathrm{F}$ made the point that there is more to the issue than just financial impact. The emotional stress that is suffered from flooding is also significant. Interviewee $\mathrm{C}$ said that "they hoped that where it is beneficial for someone to protect their property they would do this irrespective of the affordability and the availability of insurance". In the literature review however, there was little evidence to support this statement. It was found that uptake of flood protection measures is still very low. The complexity of dealing with flood risk was cited by interviewee D as a possible reason for the low uptake of these measures: "It's not as clear cut as installing a safety lock to your front door...it is less clear how these mechanisms are going to work".

It was apparent there was no simple answer to the problem of persuading householders to take up FRe technology. It was surprising that only one Interviewee (B) thought reduced premiums could be used. This reflects the perceived complexity of implementing such a scheme. Interviewee A thought that outright refusal of cover, which would make the property un-mortgageable, would be a possible driver. They also thought pilot grant schemes from Defra which have now evolved into partnership funding schemes were motivational for people. Interviewee $\mathrm{G}$ felt that people were more likely to take up flood resilient measures if they were passive, such as flood doors that look like normal doors and kite marked one way valves. "We are getting there but the PLP industry is still very young and these products are still very expensive".

Integration into building regulations and more robust planning were responses that also stood out. 


\subsection{Resistance and resilience}

In response to the question of role of resilience and resistance measures in reducing flood risk, interviewees $\mathrm{B}$ and $\mathrm{F}$ mention passive measures such as self-closing air bricks and front doors with integrated protection. These measures are favoured by insurance companies because they remove the element of human error; once installed they don't need to be set up. Interviewee F points out that

"We protect our home with burglar alarms, and smoke alarms...it seems that simple procedures could be put in place if the house is at risk of flooding”.

The most common response was that resistance and resilience measures shouldn't be taken in isolation; they should be part of a portfolio of measures. This view is supported by the literature and the EU directive that flood risks need to be dealt with in a more integrated way.

Interviewees A, B, E and G agreed that resistance and resilience should be used in conjunction with other measures. In some cases flood defences may be the most cost effective solution. Carrying out a cost/benefit analysis was highlighted by $\mathrm{C}$, $\mathrm{D}$, and $\mathrm{F}$ all mentioned that an economic assessment of cost and benefit was vital to prevent measures being carried out where they were not needed. Rural communities that are scarcely populated were places which could benefit from this. An interesting point was highlighted by interviewee $C$, who said that quite often the resilience measures are designed to protect internal fixtures and fittings that may have a design life much shorter than the expected return period of the flood. Here, it may be more cost beneficial to assume the product will need replacing by then anyway. Interviewee G points out that the word 'defences' conveys the wrong impression. It implies that they provide complete protection. The language of flood risk management is more appropriate, and the use of integrated techniques as part of a community flood action plan is more effective.

Interviewees A, B and $\mathrm{G}$ felt that for FRe technology to be promoted it needed to be interlinked with insurance premiums. Interviewee A pointed out that if bankers got involved and FRe measures suddenly became a condition of mortgages then this would encourage uptake. Interviewees C, E and F thought that flood risk was still the strategic responsibility of the Government and their agencies. Interviewee $\mathrm{E}$ made the point that for insurers to get involved, it would have to be for their own commercial advantage. Insurers are in the business to make a profit and have no social responsibility to help householders. Interviewee $\mathrm{G}$ explains that trying to get people to engage by going into communities to raise flood risk awareness is valuable, but it is trying to push the ball uphill. Using this analogy, he suggests that it also about trying to find policy levers so the ball can be pulled up hill at the same time. He suggests that one such policy lever could be to make it a condition of insurance, and this would be a strong incentive.

\subsection{Accountability and training}

A possible method of monitoring performance of FRe technology could be via stricter building codes and the benchmarking of products. Interviewee E suggested that there was scope for independent research as some manufacturers may not be able to afford the kite mark but this does not mean their products are not useful. 
From an insurer's point of view, this kind of assurance is essential because if they are ever going to offer discounts for flood protection measures they will need to know the quality of the workmanship involved. Interviewee A pointed out that there are precedents linking the benchmarking of quality with insurance. He suggests standards for sprinkler systems and burglar alarms need to be adhered to as a requirement for insurance against fire and theft. Respondent G says an in depth report on what did and didn't work in 2012 was required from the Environment Agency and Defra in order to drive up standards.

The general feeling amongst interviewees was that building professionals lacked the necessary experience and training to deal effectively with flood risk. Even from those within the surveying profession. Respondent B highlighted the complexities of the drying process was an area that needed better understanding. There was acknowledgement that there are professionals who specialise, but that for the moment they are in the minority. There are dedicated facilities in the UK, such as the National Flood School, which specialise in training in flood restoration for building professionals. There was concern with Interviewees E, D and F, that Local Authorities, with their greater responsibility for FRM, may not yet have the skills necessary to take on this role.

The response to whether we can learn from flood policies from other parts of the world was that even though there are always lessons that can be learned from other countries, there is not one specific model that will necessarily solve all the issues. Other countries will have different climates, landscapes, populations and social structures. There are many elements that forbid the applicability of a generic solution to individual cases in the UK. Interviewee D rightly suggested that the EU strategy which led to the 'making space for water' directive, has set out a comprehensive new approach and triggered a rethink in the UK as to how flooding is dealt with.

\section{Conclusions}

The research has established several key points that need to be achieved to promote and incentivise the use of property level resilience. Amongst these, stronger partnerships between insurance companies and those developing FRe technology should be established. Passive measures which are deployed automatically could be a key factor in encouraging insurance companies to reduce premiums as this would remove the element of human error when it comes to deploying these products. Insurers could be more influential in promoting and incentivising property level resilience. For this to work there needs be assurances that the products are going to reduce the amount the insurance companies pay out in the event of a flood. There needs to be standardisation, both for the products and the installation. Kite mark schemes are improving, and there are a lot more tested products on the market. However, standards for installation need to come from regulation, at the moment there is plenty of guidance and codes of practice, but in an emergency these tend to be less adhered to. A relatively small reduction in the cost of premiums will not be enough of a driver for change, because the initial costs for the installation of FRe technology may be too high. Community schemes 
need to allocate money to those households that are most vulnerable and need to encourage innovative ideas for community resilience beyond the use of FRe technology.

It has been established from the research that the provision of flood insurance does impact upon householders decisions of whether or not to install property level resilience measures. The term 'Moral Hazard' is used by many researchers to describe a tendency towards less responsible behaviour by those who believe they are insulated from financial risk by insurance. The difficulty is that if insurance is the default position then it is unlikely that householders will consider other avoidance strategies. It is important to emphasise that the measures proposed to protect the availability of affordable flood insurance under 'Flood Re', are only intended to be temporary. They will be phased out within 20-25 years, when the market will move towards risk reflective pricing. There is a danger that some householders that could benefit from FRe technology will be drawn into a false sense of security by the availability of affordable insurance. It is therefore important that during this transitional period of 'Flood Re', opportunities are taken to develop and promote flood resilience for properties which will benefit most from these measures. This assertion is backed up by the findings of the literature and the interviews, which have highlighted that property level resilience measures will need to play an increasingly important role in managing future flood risks.

\section{References}

[1] Written evidence to the Environment, Food and Rural Affairs Select Committee inquiry into flood funding. Association of British Insurers, ABI. Online. http://www.publications.parliament.uk/pa/cm201213/cmselect /cmenvfru/writev/flood/m07.htm

[2] Securing the future availability and affordability of home insurance in areas of flood risk. Department for Environment, Food and rural Affairs, DEFRA. Online. https://consult.defra.gov.uk/flooding/floodinsurance

[3] Bichard, E. \& Kazmierczak, A., Are homeowners willing to adapt to and mitigate the effects of climate change? Climate Change (2012) pp. 112: 633-644, 2011.

[4] Guidance on surface water flood mapping for lead Local Authorities. Environment Agency: Bristol, 2012.

[5] SMARTeST - Glossary. Online. tech.floodresilience.eu/attachments/article /40/smartest-glossary.pdf

[6] White, I., Lawson, N., O'Hare, P., Garvin, S. \& Connelly, A., Six Steps to Property Level Flood Protection - Guidance for local authorities and professionals: Manchester, 2012.

[7] Kazmierczak, A., and Connelly, A., Buildings and Flooding - a risk response case study. EcoCities project, University of Manchester. Manchester, 2011.

[8] Adaptation Sub-committee., Climate change - is the UK preparing for flooding and water scarcity: Adaptation Sub-Committee Progress Report 2012, Committee on Climate Change: London, 2012. 
[9] Bell, A., Morpeth Flood Action Group Insurance Survey - Results and Analysis, Online. http://www.morpethfloodaction.org.uk/survey.html

[10] Cobbing, P., and Miller, S., Property level protection and insurance: Main report-2012, National Flood Forum: Bewdley 2012.

[11] Harries, T., Review of the Pilot Flood Protection Grant Scheme in a Recently Flooded Area. Department for Environment Food and Rural Affairs: London, 2009.

[12] Lamond, J. E., Proverbs, D.G., and Hammond, F.N., Accessibility of flood risk insurance in the UK: confusion, competition and complacency, Journal of Risk Research, 12 (6), pp. 825-84, 2009.

[13] Lamond, J. E. (2012) Financial Implications of Flooding and the Risk of Flooding on Households, in: Lamond, J., Booth, C., Hammond, F., and Proverbs, D. (eds.) Flood Hazards: Impacts and Responses for the Built Environment. CRC Press: Boca Raton pp. 317-326, 2012.

[14] Priest, S.J., Clark, M.J., Treby, E.J., Flood Insurance: The challenge of the uninsured, Area 37.3 Royal Geographical Society, pp. 295-302, 2005.

[15] Lamond, J.E., Proverbs, D, G., Flood Insurance in the UK - a survey of the experience of flood plain residents, in: Proverbs, D., Brebbia, C.A., and Penning-Rowsell, E. (eds.) Flood Recovery, Innovation and Response, WIT Press: Southampton, 2008.

[16] Harries, T., Why Most “At Risk" Homeowners Do Not Protect Their Homes From Flooding, in: Lamond, J., Booth, C., Hammond, F., and Proverbs, D. (eds.) Flood Hazards: Impacts and Responses for the Built Environment, Taylor and Francis Group: Boca Raton, 2012.

[17] O'Neill, J., and O'Neill, M., Social Justice and the future offlood insurance, Joseph Rowntree Foundation: York, 2012.

[18] Botzen, W.J., Van Den Bergh, J.C.J.M., Monetary valuation of insurance against flood risk under climate change, International Economic Review, 53, pp. 1005-1026, 2012.

[19] White, I., O’Hare, P., Garvin, S., Connelly, A. (2012) Barriers to flood resilience: Findings from the SMARTEST project, The University of Manchester and BRe: Manchester, 2012.

[20] Boobier, T. (2012) The Development of Standards in Flood Damage Repair: Lessons to be learned from the United Kingdom Example in: Lamond, J., Booth, C., Hammond, F., and Proverbs, D. (eds.) Flood Hazards: Impacts and Responses for the Built Environment, CRC Press: Boca Raton, pp. 129139, 2012.

[21] Kidd, B., Tagg, A., Escarameia, M., von Christierson, B., Lamond, J., Proverbs, D. Guidance and standards for drying flood damaged buildings, Signposting current guidance - BD2760, 2010.

[22] Haigh, R. Interviews: A negotiated partnership, in: Knight, A., and Ruddick, L. (eds.) Advance Research Methods in the Built Environment. Oxford: Blackwell: Oxford, pp. 111-120, 2008. 